\title{
Characterization of raw and chemically activated natural zeolite as a potential sorbent for heavy metal ions from waste water
}

\author{
N. S. Krstić1 ${ }^{*}$, M. N. Stanković ${ }^{1}$, D. M. Đorđević ${ }^{1}$, V. D. Dimitrijević ${ }^{1}$, M. Marinković ${ }^{1}$, M. G. \\ Đorđević $^{1,2}$, A. Lj. Bojić ${ }^{1}$ \\ ${ }^{1}$ University of Niš, Faculty of Science and Mathematics, Department of Chemistry, Višegradska 33, 18000 Nǐ̌, Serbia \\ ${ }^{2}$ PUC for water supply and sewerage "Naissus", Kneginje Ljubice 1/1, 18000 Niš, Serbia
}

Received February 1, 2019; Accepted February 25, 2019

In this study, raw and chemically activated natural zeolite from Zlatokop deposit (Serbia) were investigated by FTIR, XRD, SEM-EDX, TGA and BET in order to define their properties as further potential sorption materials. Obtained results indicate porous (meso-pore range) and defined crystal alumino-silicate structure of these materials, with $\mathrm{Na}^{+}, \mathrm{K}^{+}$, such as $\mathrm{Ca}^{2+}$ and $\mathrm{Mg}^{2+}$ as dominating exchangeable cations. Content of clinoptilolite (ca. 90\%) indicates the high quality of the zeolite samples. Preliminary sorption analyses of these materials toward copper(II) ion from aqueous solution showed good removal efficiency for base activated zeolite $\left(\mathrm{zVB}_{\mathrm{B}}\right)$ compared to raw natural $\left(\mathrm{zVB} \mathrm{B}_{\mathrm{N}}\right)$ and acid activated $\left(\mathrm{zVB}_{\mathrm{A}}\right)$ zeolite. Since these were preliminary sorption tests, the investigated zeolites will be further examined under different experimental conditions.

Key words: Zlatokop zeolite, activation, FTIR, XRD, SEM-EDX, TGA, BET, heavy metal sorption.

\section{INTRODUCTION}

Zeolites are crystalline aluminosilicate minerals with structures built of $\mathrm{SiO}_{4}$ and $\mathrm{AlO}_{4}$ tetrahedra which are linked by their corners. Natural zeolites are widely used: for purification of water, soil improvement, animal food production, food supplements and additives, radioprotection, etc. [1]. The possibilities of using zeolites for pollutants removal from wastewaters have been extensively studied. Their use is also stimulated by the availability and low cost, in addition to excellent physicochemical properties, like selective sorption of different metals and non-toxic nature [2, 3]. Also, zeolites have a high surface area due to their porous and rigid structure [4]. Clinoptilolite, a member of the heulandite group (HEU type zeolite), is the most abundant natural zeolite. Its tabular morphology shows an open reticular structure of easy access exhibited by (eight- and ten-membered ring) channels $[5,6]$.

The protection and improvement of water resources have received increased attention in the world. Over the years, various materials in native form or chemically modified, have been studied for their ability to remove pollutants from wastewaters. Studied materials should be low cost, widely available and environmentally friendly. [7]

In this study characterization of raw natural zeolite and chemically activated natural zeolite from Zlatokop deposit (Serbia) was done using FTIR, XRD, SEM-EDX, TGA and BET. These zeolites were investigated as a further potential

\footnotetext{
* To whom all correspondence should be sent.

E-mail: nenad.krstic84@yahoo.com

sorbent for inorganic (heavy metal ions, anions) and/or organic (industrial colours, pesticides, drugs) pollutants from water systems. Also, preliminary sorption analyses were done (waste water model system with $\mathrm{Cu}^{2+}$ ion). Raw natural nonactivated zeolite was designated further in the manuscript as , $\mathrm{ZVB}_{\mathrm{N}}$ “, while activated zeolites were designated as , $\mathrm{ZVB}_{\mathrm{A}}$ “ (acid activation - $\mathrm{HCl}$ ) and , $\mathrm{ZVB}_{\mathrm{B}}$ “ (base activation $-\mathrm{NaOH})$.

\section{Zeolite deposit}

Zlatokop deposit is located in south-east Serbia near Vranjska Banja and represents one of the largest zeolite deposits in Serbia (Figure 1a). This zeolite deposit is related to Miocene volcanic activity and classified as high-quality zeolite deposit in Serbia (more than $70 \%$ of clinoptilolite) [8] This deposit is related to volcanic and volcanicclastic rocks of lake sediments, with estimated reserves of zeolite of $c a .0 .59 \mathrm{Mt}$ [9].

\section{EXPERIMENTAL}

Sample preparation and activation

Natural zeolite sample (Figure 1b) was crushed in an agate mortar and sieved in order to obtain fractions of different particle size. The fraction of $0.8-1.25 \mathrm{~mm}$ was washed with distilled water to remove surface dust and then dried in the oven at 100-105 ${ }^{\circ} \mathrm{C}$. Prepared material was activated with $2 \mathrm{M} \mathrm{NaOH}$ and $2 \mathrm{M} \mathrm{NaCl}$. The mixtures were stirred for $12 \mathrm{~h}$ using a magnetic stirrer at room temperature, separated by centrifugation, thoroughly washed with deionized water. The zeolite samples were dried in the oven at 100-105 ${ }^{\circ} \mathrm{C}$. 
N. S. Krstic et al.: Characterization of raw and chemically activated natural zeolite as a potential sorbent ...

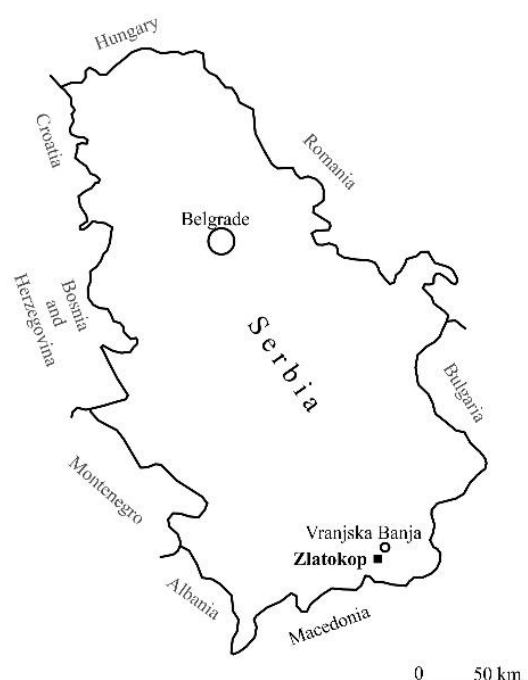

(a)

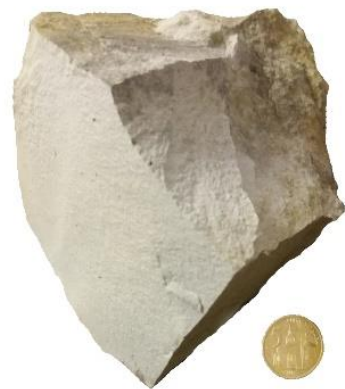

(b)

Figure 1. Geographical location of Zlatokop zeolite deposit (a) and zeolite sample (b)

\section{Fourier transform infrared (FTIR) spectrometry}

The FTIR spectra of samples were obtained by using $\mathrm{KBr}$ pellets with Fourier transform infrared spectrometer Bomem Hartmann \& Braun MB-100 in the wavelength range $4000-400 \mathrm{~cm}^{-1}$.

\section{Scanning electron microscopy with energy} dispersive X-ray spectroscopy (SEM-EDX)

The morphology of the zeolite samples surface was analyzed by SEM (Hitachi SU8030). EDS analysis (Thermo Scientific NORAN System 7, USA) provided elemental information via the analysis of X-ray emissions from the sorbent surface. For SEM-EDX analysis samples were attached to aluminum stubs using Leit-C carbon cement. Samples were imaged uncoated.

Surface area analysis using the Brunauer-EmmettTeller (BET) method

The specific surface area was measured by nitrogen adsorption using the Micromeritics Gemini 5 surface area analyzer, USA.

\section{Thermogravimetric $(T G)$ analysis}

TG analysis was performed using TGA Q5000 (TA Instruments, USA).

\section{$X$-ray diffraction $(X R D)$ analysis}

Zeolite samples were finely ground using a mortar and pestle and placed into standard sample holders. Data were collected with a Bruker D8 Advance X-ray Diffractometer (Bruker, Germany) in theta-theta geometry in reflection mode with $\mathrm{Cu}$ $\mathrm{K} \alpha$ radiation. Data collection was between $5-70^{\circ}$ $2 \theta$, step size of $0.02^{\circ}$ and a counting time of $1 \mathrm{sec}$ per step.

\section{Preliminary sorption experiment}

Preliminary sorption abilities of raw and chemically modified zeolites were investigated in a model system with copper(II) ion as we have done in our previous investigations. The concentrations of $\mathrm{Cu}(\mathrm{II})$ ions in the solution before and after adsorption were determined by using an atomic absorption spectrophotometer (AAnalyst 300, Perkin Elmer, USA) [7, 10].

\section{RESULTS AND DISCUSSION}

FTIR. The FTIR spectra of zeolite samples recorded in the wavelength region between 400 and $4000 \mathrm{~cm}^{-1}$ are shown in Figure 2.

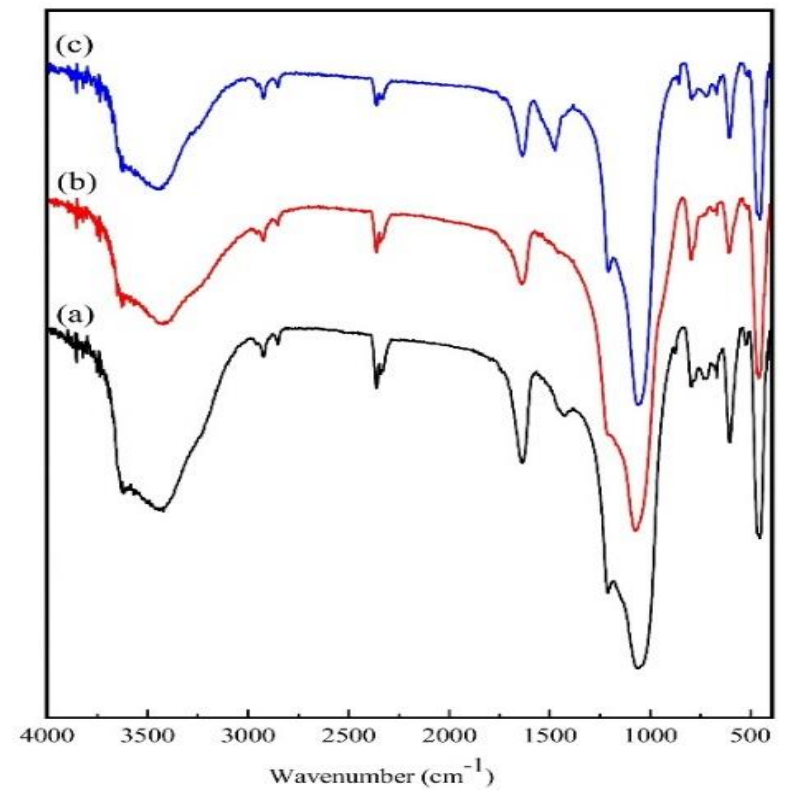

Figure 2. FTIR spectra of $\mathrm{zVB}_{\mathrm{N}}(\mathrm{a}), \mathrm{zVB}_{\mathrm{A}}$ (b) and $\mathrm{zVB}_{\mathrm{B}}(\mathrm{c})$.

Characteristic bands for natural zeolite can be identified. Wide band between 2900 and $3750 \mathrm{~cm}^{-1}$ 
N. S. Krstic et al.: Characterization of raw and chemically activated natural zeolite as a potential sorbent ... is attributed to the existence of $\mathrm{OH}$ group stretching vibrations (from $\mathrm{Al}-\mathrm{Al}-\mathrm{OH}$ or present water). Deformation vibration of molecularly bound water in the zeolite structure is characterized by bands in the spectra in the region $1600-1650 \mathrm{~cm}^{-1}$. The bands in the range $950-1250 \mathrm{~cm}^{-1}$ correspond to asymmetric stretching vibration of structural tetrahedra units of the aluminosilicate lattice $\mathrm{Si}(\mathrm{Al})-\mathrm{O}$ of the zeolite. The bands in the range $455-790 \mathrm{~cm}^{-1}$ correspond to stretching vibration of $\mathrm{O}-\mathrm{Si}(\mathrm{Al})-\mathrm{O}$ groups and bending vibrations of $\mathrm{Si}(\mathrm{Al})-\mathrm{O}$ bonds. According to the obtained data there are no significant changes in the FTIR spectra after chemical modification of natural zeolite, but it was confirmed that these are aluminosilicate materials with defined crystal structure [11, 12].

SEM-EDX. SEM micrographs of the investigated zeolite samples are presented on Figure 3. These micrographs show the porous and well-defined crystal structure of natural and modified zeolite samples.

EDX analysis was done by measuring different parts of the sample (seven points) in order to get more precise elemental compositions of the investigated samples (Figure 4).

Data from Figure 4 indicate the aluminosilicate structure of zeolite with $\mathrm{Na}^{+}, \mathrm{K}^{+}$, such as $\mathrm{Mg}^{2+}$ and $\mathrm{Ca}^{2+}$ as dominating exchangeable cations. Average values of these ions are decreasing after zeolite

(a)

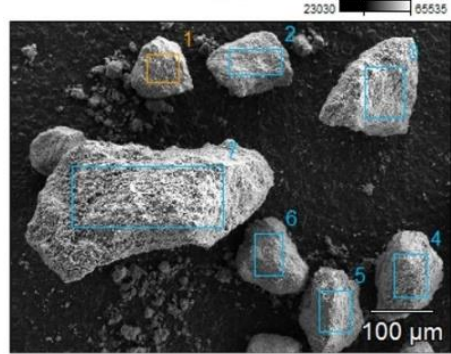

activation with hydrochloric acid for $\mathrm{Na}^{+}$and $\mathrm{K}^{+}$by ca. $90 \%$, while for $\mathrm{Ca}^{2+}$ and $\mathrm{Mg}^{2+}$ ions by ca. $55 \%$. After base activation $\mathrm{Na}^{+}$value increases $(c a$. six times), $\mathrm{K}^{+}$and $\mathrm{Ca}^{2+}$ decrease (by ca. $20 \%$ and $10 \%$, respectively), while there are no changes for $\mathrm{Mg}^{2+}$ value. All these changes are the result of ion exchange processes after acid and base modifications $\left(\mathrm{H}^{+}\right.$or $\mathrm{Na}^{+}$or $\mathrm{OH}^{-}$ions). These results are in accordance with literature data for zeolites from the Balkan region [13, 14].

$X R D$. XRD diffractograms of $\mathrm{zVB}_{\mathrm{N}}, \mathrm{zVB}_{\mathrm{A}}$ and $\mathrm{zVB}_{\mathrm{B}}$ samples are shown on Figure 5. According to the data from Figure 5 the dominant zeolite's mineral is clinoptilolite ( $c a .90 \%$ ), which confirms the appearance of an intense peak at the $2 \theta$ angle of $22^{\circ}$ [15]. XRD data also showed that the investigated natural zeolite contains other minerals quartz, mordenite, albite and calcite in minority. Comparing XRD diffractograms of $\mathrm{zVB}_{\mathrm{N}}, \mathrm{zVB}_{\mathrm{A}}$ and $\mathrm{zVB}_{\mathrm{B}}$ it can be noticed that there are no significant differences between natural and chemically modified zeolites, except the disappearance of the calcite peak at the $2 \theta$ angle of around $29.5^{\circ}$ [16] in the sample $\mathrm{zVB}_{\mathrm{A}}$, due to dissolving calcite in hydrochloric acid, which is in accordance with the EDX results where a decrease of carbon value by $c a .45 \%$ after acid and by $c a$. $20 \%$ after base activation can be noticed (Figure 4 ).

Figure 3. SEM micrographs of $\mathrm{zVB}_{\mathrm{N}}(\mathrm{a}), \mathrm{zVB}_{\mathrm{A}}(\mathrm{b})$ and $\mathrm{zVB} \mathrm{B}_{\mathrm{B}}(\mathrm{c})$.
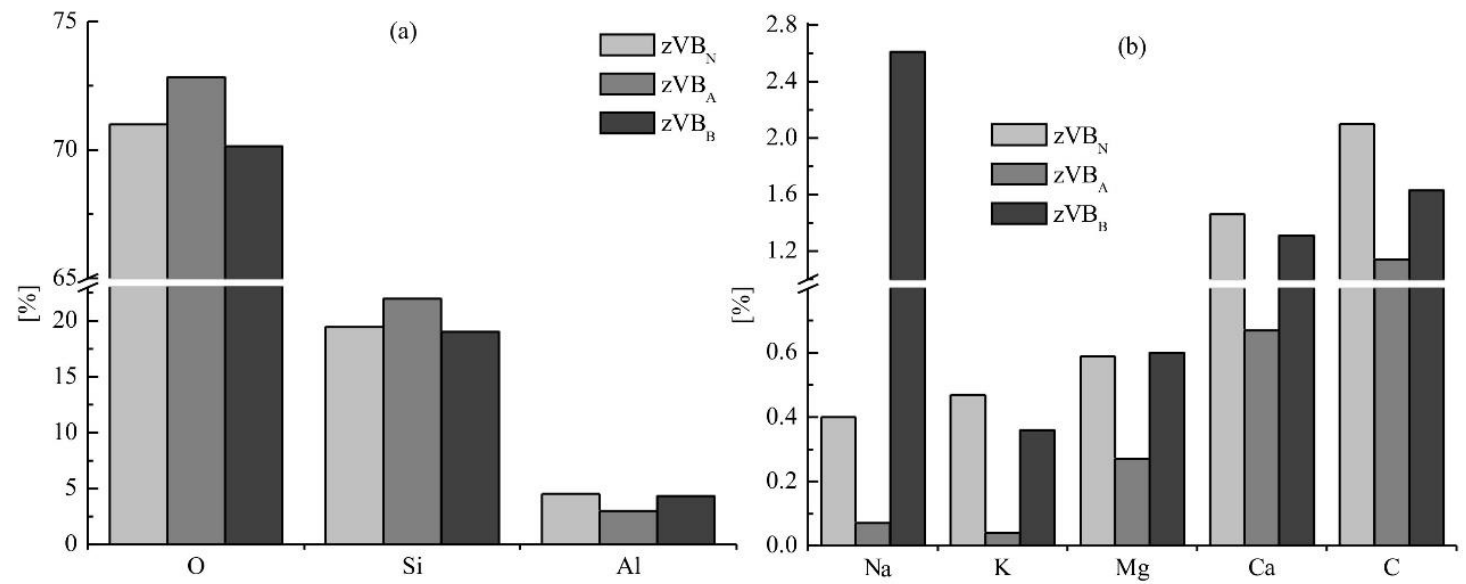

Figure 4. EDX analysis of average elements in zeolite samples [atom \%, error \pm 2 sigma; total 100\%] 
N. S. Krstic et al.: Characterization of raw and chemically activated natural zeolite as a potential sorbent ...

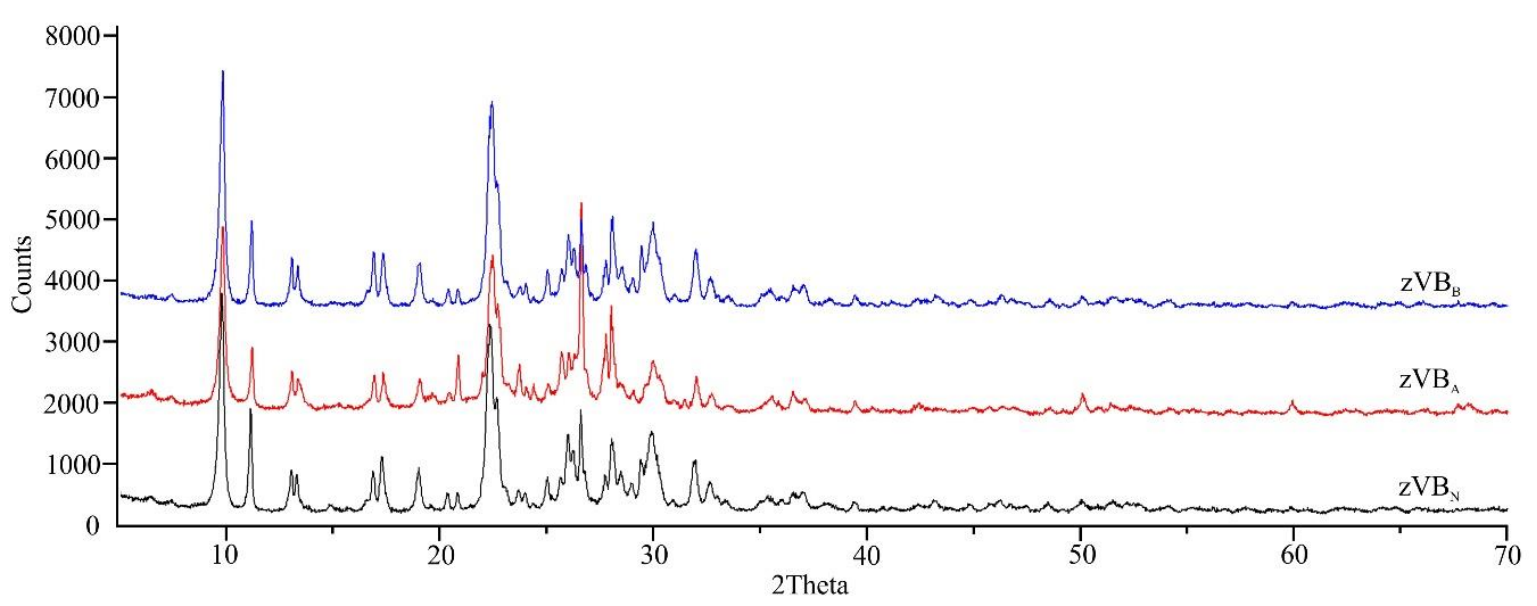

Figure 5. XRD diffractograms of zeolite samples

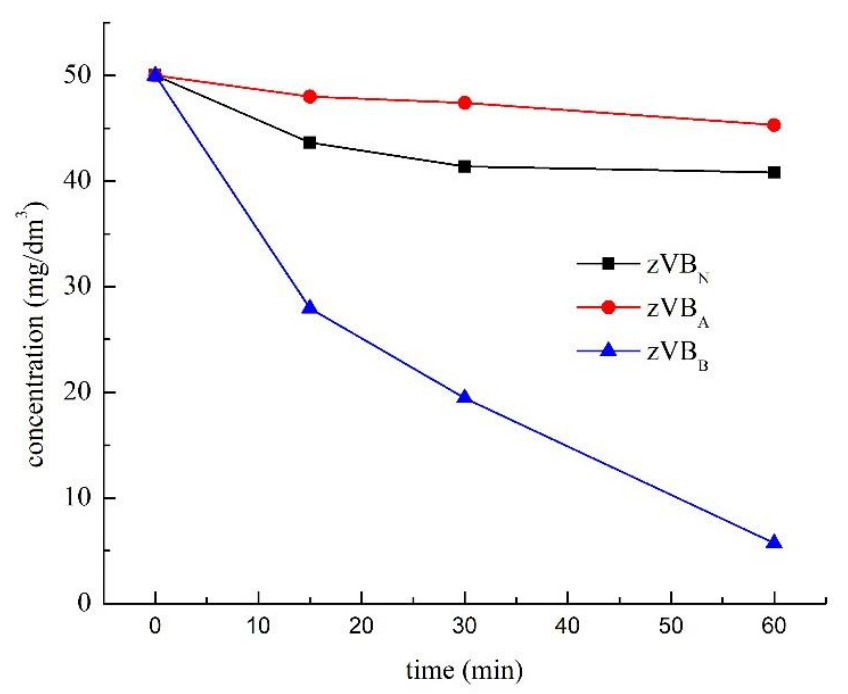

Figure 6. Effect of contact time on the removal of $\mathrm{Cu}(\mathrm{II})$ by zeolite materials

Table 1. Textural properties of the zeolite samples

\begin{tabular}{cccc}
\hline Sample & $\begin{array}{c}\text { BET surface area } \\
\mathrm{S}_{\mathrm{BET}}\left(\mathrm{m}^{2} \mathrm{~g}^{-1}\right)\end{array}$ & $\begin{array}{c}\text { Average pore } \\
\text { diameter }(\mathrm{nm})\end{array}$ & $\begin{array}{c}\text { BJH cumulative desorption pore } \\
\text { volume }\left(\mathrm{cm}^{3} \mathrm{~g}^{-1}\right)\end{array}$ \\
\hline $\mathrm{zVB}_{\mathrm{N}}$ & 22.87 & 15.42 & 0.0863 \\
$\mathrm{zVB}_{\mathrm{A}}$ & 21.47 & 15.17 & 0.0746 \\
$\mathrm{zVB}_{\mathrm{B}}$ & 31.79 & 15.39 & 0.1316 \\
\hline
\end{tabular}

Preliminary sorption results. The preliminary results of the sorption abilities of the obtained zeolite (particle size $0.8-1.25 \mathrm{~mm}$ ) materials toward copper(II) ions in aqueous solution are shown in Figure 6. These results indicate that raw unmodified natural zeolite $\left(\mathrm{zVB}_{\mathrm{N}}\right)$ and zeolite modified with hydrochloric acid $\left(\mathrm{zVB}_{\mathrm{A}}\right)$ show similar, but not significantly efficient sorption properties. Copper removal efficiency, RE (\%) is ca. $19 \%$ for $\mathrm{zVB}_{\mathrm{N}}$ and $c a$. $10 \%$ for $\mathrm{zVB}_{\mathrm{A}}$. By treatment with sodium hydroxide $\left(\mathrm{zVB}_{\mathrm{B}}\right)$ better sorption properties (RE, ca. $90 \%$ ) than $\mathrm{zVB}_{\mathrm{N}}$ and $\mathrm{zVB}_{\mathrm{A}}$ for removal of $\mathrm{Cu}(\mathrm{II})$ ions from wastewater were achieved. The concentration of copper declined sharply with contact time in the first 15 minutes and continued this trend in the range of investigated contact time.

Clinoptilolite is a porous crystal material, which adsorption properties are strongly related to the framework structure, which has performance for physical adsorption and ion exchange [17]. According to the ion exchange mechanism, ions present in the pores of zeolite crystalline lattices are substituted by toxic metal ions from the solution. The ion exchange process is reversible, and the zeolite may be recovered for further use [14].

Surface area analysis. Table 1 summarizes the results of the textural properties of the tested zeolite samples. In comparison with the results of other authors, very similar values of specific surface area, 
N. S. Krstic et al.: Characterization of raw and chemically activated natural zeolite as a potential sorbent ... mean pore diameter and pore volume were determined for (unmodified) raw zeolite $\left(\mathrm{zVB}_{\mathrm{N}}\right)$ and the acid treated zeolite $\left(\mathrm{zVB}_{\mathrm{A}}\right)[18]$. A sample of zeolite treated with $\mathrm{NaOH}\left(\mathrm{zVB}_{\mathrm{B}}\right)$ shows a significant increase in the BET specific surface area and $\mathrm{BJH}$ cumulative desorption pore volume. Increase in the specific surface area of the sample $\left(\mathrm{zVB}_{\mathrm{B}}\right)$ can be possibly related with the phenomenon of presence of cations or minerals which block the pore channels, so the limited extent of zeolite crystalline structure reduces its sorption activity [19], but treatment with $\mathrm{NaOH}$ produces an improved adsorbent which is confirmed by the results of the adsorption. The increase in the mesopore volume of the $\mathrm{NaOH}$-treated clinoptilolite is probably caused by unblocking of the channels of the aluminosilicate framework structure of the zeolite through dealumination and decationation during base leaching, and possibly also by dissolution of any amorphous silica blocking the channels of the clinoptilolite structure [20]. All of the above leads to the improvement of the adsorption activity of the mentioned $\left(\mathrm{zVB}_{\mathrm{B}}\right)$ zeolite sample.

The $\mathrm{N}_{2}$ adsorption/desorption isotherms of the zeolite samples showed a typical $s$-shape behavior of IV-type with a type-H3 of hysteresis loop that indicated the existence of mesopores (Figure 7a). The clinoptilolite samples have characteristic presence of this type of hysteresis loop, which can be attributed to multilayer adsorption followed by capillary condensation either in mesopores of impurities (feldspars, quartz, etc.) or in the space developed between the zeolite crystallites [21]. The pore system of all tested zeolite samples is in the meso-pore range between bimodal distributed pores characterized with maxima in pore size between 2 $5 \mathrm{~nm}$ and $10-50 \mathrm{~nm}$ with an average pore diameter around $15 \mathrm{~nm}$ in size according to the $\mathrm{BJH}$ desorption isotherms (Figure 7b).
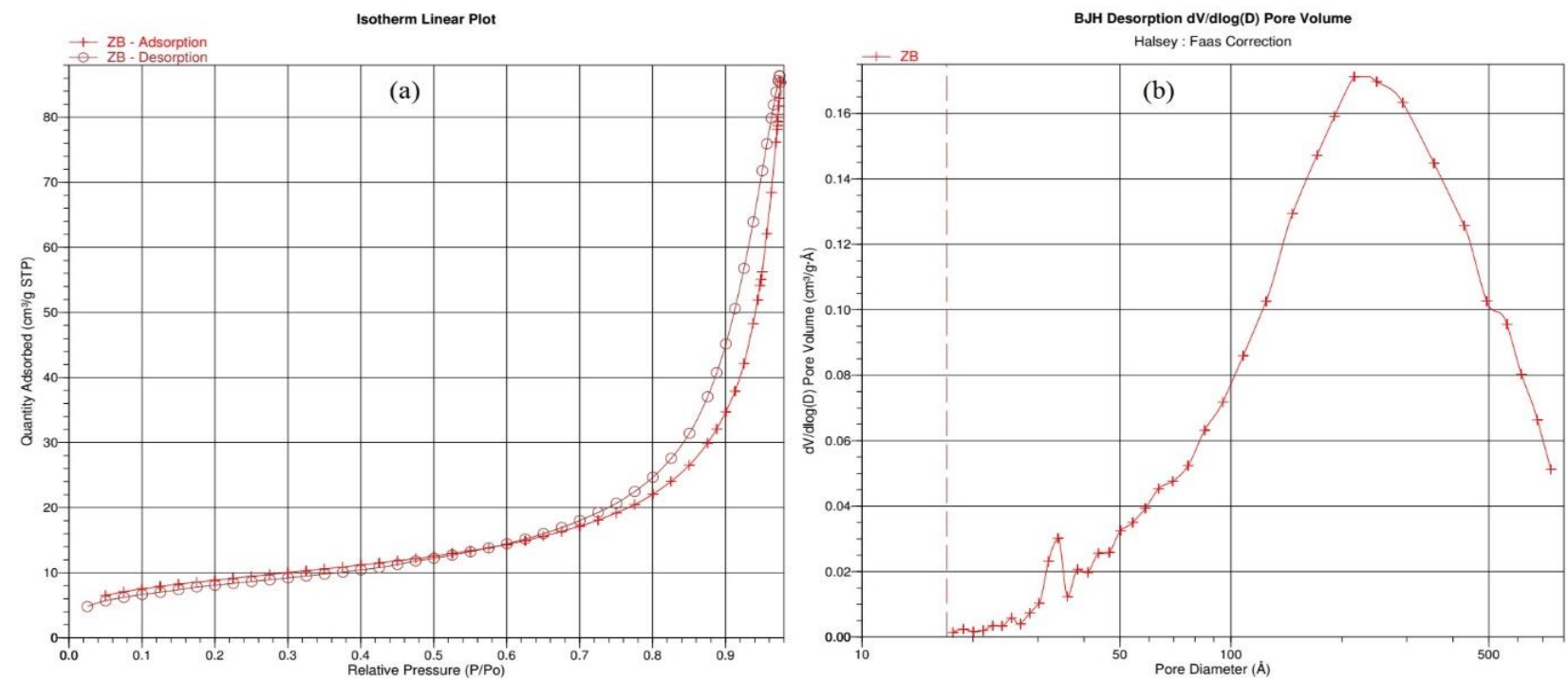

Figure 7. $\mathrm{N}_{2}$ adsorption/desorption isotherm of $\mathrm{zVB}_{\mathrm{B}}$ sample (a) and pore size distribution for $\mathrm{zVB} \mathrm{B}_{\mathrm{B}}$ sample (b)

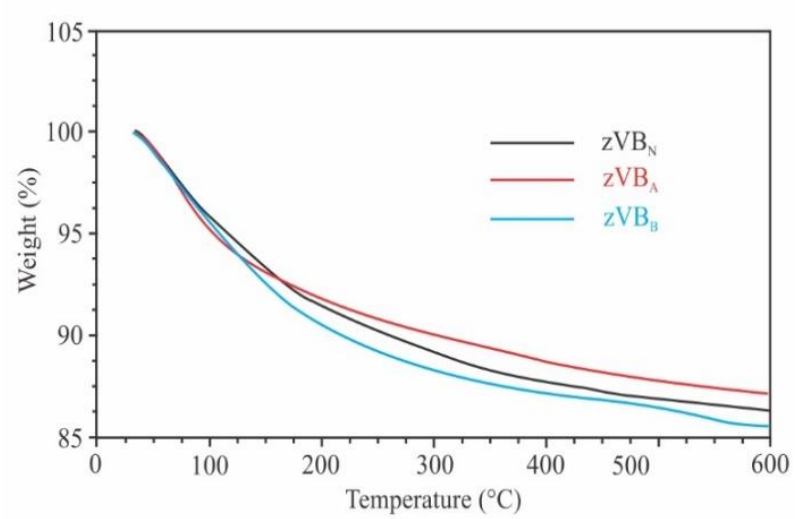

Figure 8. TG curves of the zeolite samples

$T G$ analysis. The results of thermogravimetric analysis of the tested zeolite samples are summarized in Figure 8. Thermal treatment of the zeolite samples leads to a loss of mass in the range $20-600{ }^{\circ} \mathrm{C}$, because of surface dehydratation and dehydroxylation.

The process of zeolitic water elimination is held in a few stages. At temperatures below $100{ }^{\circ} \mathrm{C}$ physically adsorbed water is mainly eliminated, further increase of temperature in the range 100$300{ }^{\circ} \mathrm{C}$ or higher, leads to removal of hydroxyls through the associative desorption mechanism. At temperatures in the range $200-600{ }^{\circ} \mathrm{C}$ almost all hydroxyl groups leave the surface, moreover the isolated $\mathrm{OH}$ groups are eliminated at higher temperatures. Changes in temperature of zeolitic water elimination can be a consequence of the presence of different exchangeable cations in zeolites [22]. Based on the results of the 
N. S. Krstic et al.: Characterization of raw and chemically activated natural zeolite as a potential sorbent ... thermogravimetric analysis of the tested zeolite samples presented in Figure 8 it can be noticed that the elimination of intact water is observed up to 120 ${ }^{\circ} \mathrm{C}$. The most essential loss of mass is observed at 120-400 ${ }^{\circ} \mathrm{C}$ because of associative desorption of hydroxy species and desorption of intact water. A sample of zeolite $\left(\mathrm{zVB}_{\mathrm{B}}\right)$ treated with $\mathrm{NaOH}$ shows the largest loss of mass ( $\mathrm{ca} .14 .50 \%)$, unlike the samples $\mathrm{zVB}_{\mathrm{K}}$ and $\mathrm{zVB}_{\mathrm{N}}$ with mass loss (ca. $12.90 \%$ and $c a .13 .70 \%$, respectively), which can be possibly related to the increase in the specific surface area of the sample $\left(\mathrm{zVB}_{\mathrm{B}}\right)$. Moreover, differences in TG curves presented in Figure 8 can be related to differences in complex connectivity of pores and variation in their sizes as a result of exchangeable cation replacement with protons.

\section{CONCLUSION}

According to the obtained results based on FTIR, XRD, SEM-EDX, TGA and BET analyses, the investigated zeolite from Zlatokop deposit (Serbia) is aluminosilicate material with defined crystal structure and high quality (ca. 90\% clinoptilolite) with a pore system in the meso-pore range. Preliminary results of the investigated zeolite materials $\mathrm{zVB}_{\mathrm{N}}, \mathrm{zVB}_{\mathrm{A}}$ and $\mathrm{zVB}_{\mathrm{B}}$ toward removing copper(II) ions from aqueous solution showed good sorption characteristics of $\mathrm{zVB}_{\mathrm{B}}$ zeolite (particle size $0.8-1.25 \mathrm{~mm}$ ), which is in accordance with the data obtained by BET and TGA analyses. Since these were preliminary sorption tests, zeolites (raw and activated) will be further examined with the aim to improve their sorption properties, both for inorganic and organic water pollutants, under different experimental conditions (longer contact time, different particle size of zeolite - using natural zeolite with much smaller particle size (zeolite powder), temperature, dose of sorbent, etc.).

Acknowledgement: This work was supported by the Ministry of Education, Science and Technological Development of the Republic of Serbia under the Project TR34008.

\section{REFERENCES}

1. M. Tomasevic-Canovic, J. Serb. Chem. Soc., 70, 1335 (2005).

2. H. Cui, L. Y. Li., J. R. Grace, Water Res., 40, 3359 (2006).
3. G. Yuan, H. Seyama, M. Soma, B. K. G. Theng, A. Tanaka, J. Environ. Sci. Health, 34, 625 (1999).

4. E. Alvarez-Ayuso, A. Garcia-Sanchez, X. Querol, Water Res., 37, 4855 (2003).

5. N. Rajic, Dj. Stojakovic, S. Jevtic, N. Zabukovec Logar, J. Kovac, V. Kaucic, J. Hazard. Mater., (172), 1450 (2009).

6. A. Radosavljevic Mihajlović, A. Došen, J. Stojanović, V. Kašić, V. Simić, Proceedings of the 5th Serbian-Croatian-Slovenian Symposium on Zeolites, Zlatibor, Serbia, 116 (2013).

7. M. N. Stankovic, N. S. Krstic, J. Z. Mitrovic, S. M. Najdanovic, M. M. Petrovic, D. V. Bojic, V. D. Dimitrijevic, A. Lj. Bojic, New J. Chem., 40, 2126 (2016).

8. V. Simić, D. Životić, N. Andrić, A. RadosavljevićMihajlović, V. Kašić, $9^{\text {th }}$ International Conference on the Occurrence, Properties and Utilization of Natural Zeolites, Belgrade, Serbia, 217 (2014).

9. R. Jelenković, A. Kostić, D. Životić, M. Ercegovac, Geol. Carpath., 59(4), 345 (2008).

10. M. N. Stanković, N. S. Krstić, I. J. Slipper, J. Z. Mitrović, M. D. Radović, D. V. Bojić, A. Lj. Bojić, Aust. J. Chem., 66(2), 227 (2012).

11. W. Mozgawa, M. Krol, K. Barczyk, Chemik., 65(7), 667 (2011).

12. K. Byrappa, B.V. Suresh Kumar, Asian J. Chem., 19(6), 4933 (2007).

13. N. Popov, T. Popova, J. Rubio, S. R. Taffarel, Geochem. Mineral. Petrol. 49, 83 (2012).

14. S. Cerjan Stefanovic, N. Zabukovec Logar, K. Margeta, N. Novak Tusar, I. Arcon, K. Maver, J. Kovac, V. Kaucic, Micropor. Mesopor. Mat., 105, 251 (2007).

15. M. M. J. Treacy, J. B. Higgins, Collection of simulated XRD powder patterns for zeolites, Elsevier, 2001.

16. http://rruff.info/Calcite/R050128

17. X. Li, C. Lin, Y. Wang, M. Zhao, Y. Hou, Clinoptilolite Adsorption Capability of Ammonia in a Pig Farm, Procedia Environ. Sci., 2, 1598 (2010).

18. D. A. Kennedy, M. Mujčin, C. Abou-Zeid, F. H. Tezel, Micropor. Mesopor. Mat., 274, 327 (2019).

19. M. A. Hernandez, F. Rojas, V. H. Lara, J. Porous Mater., 7, 443 (2000).

20. O. Korkuna, R. Leboda, J. Skubiszewska-Ziemba, T. Vrublevska, V. M. Gunko, J. Ryczkowski, Micropor. Mesopor. Mater., 87, 243 (2006).

21. E. Kouvelos, K. Kesore, T. Steriotis, H. Grigoropoulou, D. Bouloubasi, N. Theophilou, S. Tzintzos, N. Kanelopoulos, Micropor. Mesopor. Mater., 99, 106 (2007).

22. M.W. Kasture, P.N. Joshi, H.S. Soni, V.V. Joshi, A.L. Choudhari, V.P. Shiralkar, Adsorp. Sci. Technol., 16, 135 (1998). 